\title{
CAPACITY OF THE TOURISM AND THE ROLE OF CREATIVE INDUSTRIES - PERCEPTION OF VISITORS, BARRIERS AND MOTIVATION
}

\section{MONIKA TOMCZYK}

University of Szczecin, Faculty of Management and Economics of Services, POLAND

e-mail: monika.tomczyk@wzieu.pl

\begin{abstract}
RECEIVED
18 January 2018

ACCEPTED

2 September 2018

JEL

CLASSIFICATION

010, R11

KEYWORDS

creative industry, tourism, cross boarder

ABSTRACT The aim of this paper is to present the impact of cross-border aspects and role of creative industry on the tourists' perception as a demand side of the markets in the region of Szczecin Lagoon. Tourism Carrying Capacity should be understood as a tool supporting process of the tourism management aiming at creating regional strategic documents in the end, creative industries are the engine of change and attraction for tourists.
\end{abstract}

\section{Introduction}

The aim of this paper is to present the impact of cross-border aspects and role of creative industry on the tourists' perception as a demand side of the markets in the region of Szczecin Lagoon. Nowadays there are areas that are particularly important and associated with the evolution of the economy and knowledge-based society. The term "creative industries" is not only one of the today's buzz words but is an integral part of the structure 
of regional economy. Located at the interface of culture and economy, the creative industries in the 21st century evoke positive effects in the areas of business, technology, and society and is a driving force for creative regions. Talking about economic growth the sustainability has to be in focus. Sustainability in tourism as an economical factor in the regional development is defined by the capacity of the region as a destination. The tourism capacity of regions depends on several aspects and should not be taken into consideration only as a capacity defined by environment but should be discussed in a much wider context. As a starting point for discussion, the author of the article takes the definition of a sustainable tourism of the WTO that says that tourism capacity is: „The maximum number of people that may visit a tourist destination at the same time, without causing destruction of the physical, economic, socio-cultural environment and an unacceptable decrease in the quality of visitors' satisfaction" (WTO, 1981; PAP/ RAC, 1997). Thus, the sustainable tourism should be discussed taking into consideration three components as main pillars: physical-ecological component, socio-demographic component and political-economic component. All those elements are the fields where facts and subjective perception of stakeholders and visitors meet. The article focuses on the Szczecin Lagoon as a cross-border area and presents a perception of the visitors of the region as a one integrated German-Polish destination. As a core element, the barriers and motivation of the visitors to visit both parts of the region are presented and discussed. The survey was done separately for both sides of the Szczecin Lagoon and results from the German and Polish areas were compared. Authors analysed the potential determining factors that could influence the decision of the tourists to visit both parts of the region. The survey presents not only infrastructural or economical aspects determining positive or negative decision to share the time spent by visitors in the Szczecin Lagoon on both sides (German and Polish) but also so called soft factors like cultural heterogeneity or events having impact on the attractiveness of the region as an integrated tourism destination.

\section{Litepature review}

The concept of the Tourism Carrying Capacity should be understood as a tool supporting process of the tourism management aiming at creating regional strategic documents in the end. The definition-assessment and implementation of TCC needs to be considered as a process within a planning process for tourism development and should not be treated as a fixed framework. The World Tourism Organisation defines the Carrying Capacity in tourism as "The maximum number of people that may visit a tourist destination at the same time, without causing destruction of the physical, economic, socio-cultural environment and an unacceptable decrease in the quality of visitors' satisfaction" (PAP/RAC, 1997).

Already in the beginning of 80 's started the dialog initiated by international organisations (like e.g. World Tourism and Travel Council (WTTC), International Federation of Operators, (IFTO)) bringing on the scientific agenda the sustainable development with the environmental protection in its centre. Additionally, the possibility of the measurement of the regional tourism capacity became a second important aspect of the discussion. Because of the focus on physical-environmental elements in the first step, the maximal capacity of the tourism was defined only by those aspects. In the second development phase of the TCC concept, social and economic aspects were taken into consideration. Talking about the sustainable tourism, Briassoulis (2002) and Robinson (2000) show specific relation between human activity and natural resources on the one hand. On the other hand, the tourism activities imply interaction and conflicts (see Figure 1) between two or more interest groups among the local community and tourists (one or more groups of tourists). 


\begin{tabular}{|c|c|c|c|}
\hline & & \multicolumn{2}{|c|}{ Residents } \\
\hline & & good & bad \\
\hline \multirow{2}{*}{ Tourists } & good & $\begin{array}{l}\text { Symbolic coexistence } \\
\text { (Lichen model) }\end{array}$ & $\begin{array}{l}\text { Conflict coexistence } \\
\text { with adverse selection }\end{array}$ \\
\hline & bad & $\begin{array}{l}\text { Conflict coexistence with } \\
\text { crowding out effect }\end{array}$ & $\begin{array}{l}\text { Entropic coexistence } \\
\text { (Locus model) }\end{array}$ \\
\hline
\end{tabular}

Figure 1. Qualitative matrix of the communities' interaction

Source: Bimonte, Punzo (2007), p. 81.

As a consequence, tourism sustainability depends on quality of resources in a broad meaning, including also such aspects like human, environmental, cultural and artistic heritage (Bimonte, Punzo, 2007). The interaction of all those elements as a profile of the tourism destination is often overlooked and do not considered as factors influencing carrying capacity on the demand side. Therefore, the supply side from the perspective of the region and its direct and indirect benefits should be taken into consideration. Thus, an upper and a lowerlimit of TCC can be of more use than a fixed value. TCC assessment should provide notonly the maximum but also the minimum level of development that is the lowest level necessary for sustaining local communities. It means than that the level of tourism development between both breaking points (max. and min.) is the development intensity that has a positive impact on both: supply side (socioeconomic situation in the region) and demand side (satisfaction degree of tourists as customers).

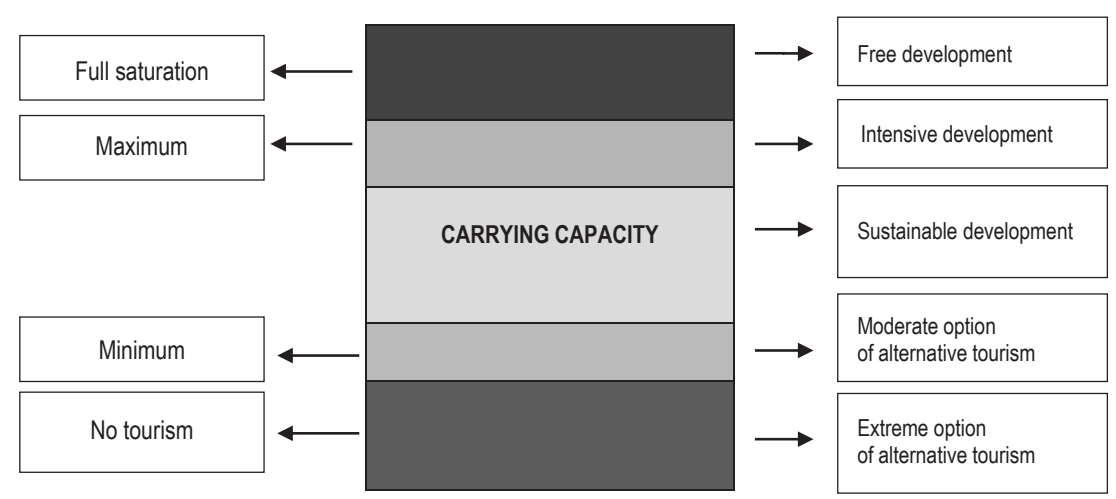

Figure 2. Scheme of the relationship between alternative development level of tourism (scenarios) and carrying capacity Source: PAP/RAC (1997), p. 27.

As a TCC concept defines carrying capacity as a process, even when this is achieved, this limit does not necessarily obey to objectively, unchangeable, everlasting criteria (Coccossis, Mexa, 2002). To summarise, TCC concept supports decision-making processes in the regional development by defining bottlenecks in the 
socioeconomic structure of the region. Additionally, recommends solutions based on cost-benefits analysis of reduction of negative impact of single elements in the regional framework.

Creative industries are becoming increasingly important components of modern post - industrial knowledge based economies. Not only they are thought to make higher then average growth and job creation, but also to be vehicles of cultural identity that play an important role in fostering cultural diversity.

According to the UNESCO definition the term creative industries refers to these organizations which combine the creation, production and commercialization of creative contents. UNESCO in 1986 has made the framework that was subsequently adopted by various national institutions which then adapted and modified the methodology to reflect the specific cultural realities of their country. The FCS defines ten distinct categories: (0) cultural heritage; (1) printed matter and literature; (2 \& 3) music and the performing arts; (4) visual arts; (5 \& 6) audiovisual media (5 cinema and photography; 6 radio and television); (7) socio cultural activities; (8) sports and games; (9) environment and nature.

The framework also proposes cross-category matrices such as creation/production, transmission/ dissemination, consumption, registration/protection and participation.

In Poland, the best-known definition of the creative industries is the British definition created by Department for Culture, Media and Sport that says, "creative industries are those industries which have their origin in individual creativity, skill and talent and which have a potential for wealth and job creation through the generation and exploitation of intellectual property" (DCMS 2001, p. 4). The current DCMS definition recognises eleven creative sectors. They are:

- advertising,

- architecture,

- arts and antique markets,

- crafts,

- design,

- designer fashion,

- film, video and photography,

- software, computer games and electronic publishing,

- music and the visual and performing arts,

- publishing,

- television,

- radio (DCMS, 2006).

The adjunct sector for the creative one is the cultural sector that has a real impact on the tourism. Cultural industries include industries that focus on heritage, museums and libraries, sports and outdoor activities, and a variety of 'way of life' activities that probably range is from local pet shows to a host of hobbyist concerns. In Germany both sectors are known as a Kulturwirtshaft. Both industries are created by creative class, the term created by Florida. Florida says that creative class consists of:

1. Super creative core - according to Florida, the wider range of disciplines from scientists, engineers, computer programmers, researchers, as well as those involved in art, design and media. "It consists of both the scientists and engineers, academics, poets and architects, as well as people who care about 
design, education, art, music and entertainment, whose economic function is to create new ideas, new technologies and/or creative content."

2. Creative professionals - other workers using knowledge (knowledge intensive Employees). They are workers with thorough preparation of the scientific community working in sectors such as health care, business, finance, law and education, justice and governance. "They solve specific problems based on advanced skills"; acquired in the course of higher education.

Szczecin is one of the oldest and biggest cities in Poland - 3rd place in terms of occupied area and 7th in terms of population. The city is the centre of agglomeration of Szczecin, a network of surrounding municipalities. According to data from 30 June 2016, the city had 405,413 inhabitants. After the second World War, almost 100\% of the area was settled by the new population, derived mainly from the typically rural, culturally backward areas. The settlers felt the double strangeness of the new environment: the civilization, because they found enormous differences between the infrastructure of modern cities and the underdevelopment and backwardness villages, and cultural, as these cities, despite the intensive propaganda of communist regime, had little in common with Polish culture (Kubicki, 2010).Rapid and profound changes in the last two decades, happening both in the microand macro-scale, make that we can observe the processes of "boom" of cities, creating a strong foundation for the development of the middle class and urban culture. The change of the system in 1989 laid the foundations for economic and legal framework for the development of the middle class, which means that it is de facto an urban middle class, which recruits mainly from the second and third generations of post war migration, the first decades of generations that can inherit the financial capital stable and predictable reality. The research of Paweł Kubicki from "Instytut Obywatelski" shows the poor condition and lack of development of the Szczecin city. Although Szczecin has a big potential of creative class and creative institutions, cannot as yet find itself in the new reality. The city is in a crisis yet failed to create the foundations for the development of new post ford economy, which could minimize the effects of the collapse of traditional industries. The key problems are lack of public spaces and the weakness of cultural institutions.

On the other hand, the quantitative research "Kultura w Szczecinie; Różnorodność, Aktywność, Wielobiegowość", which took into account the creative industry and was conducted in the city in 2010, indicates that Szczecin is a city of great creative potential. It says that Szczecin is in the process of identification and rapid development. Taking into consideration recent years, the development of cultural activities in Szczecin was in many ways faster and more intense than in other Polish cities as Kraków, Wrocław or Poznań, which are traditionally identified with culture.

So, at what point of creative industries' development is the city of Szczecin nowadays? Is the creative sector likely to become a driving force for this city? Does Szczecin meet the basic conditions reported by Florida on that topic to attract the creative class? What is the role of the soft factors such as cultural heritage, ethnic diversity, tolerance, attractive places to live, a sense of security in the development of the city? 


\section{Method}

The process of defining TCC is composed of two parts (it follows in principle the conceptual framework for TCC as described by Shelby and Heberlein, 1986).
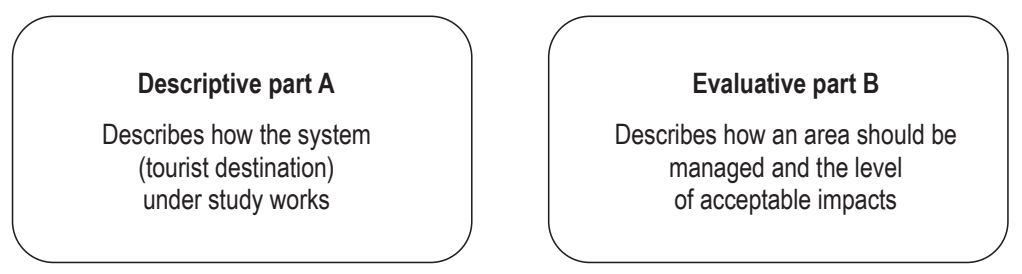

Figure 3. Two parts of defining TCC

Source: Shelby, Heberlein (1986) in Coccossis, Mexa (2002).

Part A describes the system, how it works taking into consideration broad aspects of the sustainability aspects and barriers (bottlenecks, constrains etc.). Part B on the other hand presents how the region should be managed, based on the preferable level and kind of the tourism activities in the region. The whole process of the tourism planning process based on the both parts is presented by Figure 4. The authors focus in this article on the narrow part of the whole process taking into consideration aspects playing crucial role as attractors and obstacles for customers to visit both parts (Polish and German) of the Szczecin Lagoon.

Methodological assumptions of the research relate to the Szczecin's Lagoon area. The Lagoon is an inland water basin found in the south-western part of the Baltic Sea. It is shared by Germany and Poland. These are the towns that can be found at the Szczecin Lagoon: Świnoujście, Ueckermünde, Wolin (town) and Nowe Warpno. For the needs of research also city of Szczecin is included. Szczecin as a biggest city in the region can be the touristic attraction, as well as a centre of the creative/culture industries. The survey was done in August 2017 in the Szczecin Lagoon region on both sides - Polish and German. Altogether 246 persons spending their holidays were interviewed. For the interview, the standardised questionnaire was used to ensure comparability of the survey results. The questionnaire was prepared in Polish and German language and was presented to the tourists in their national languages. 


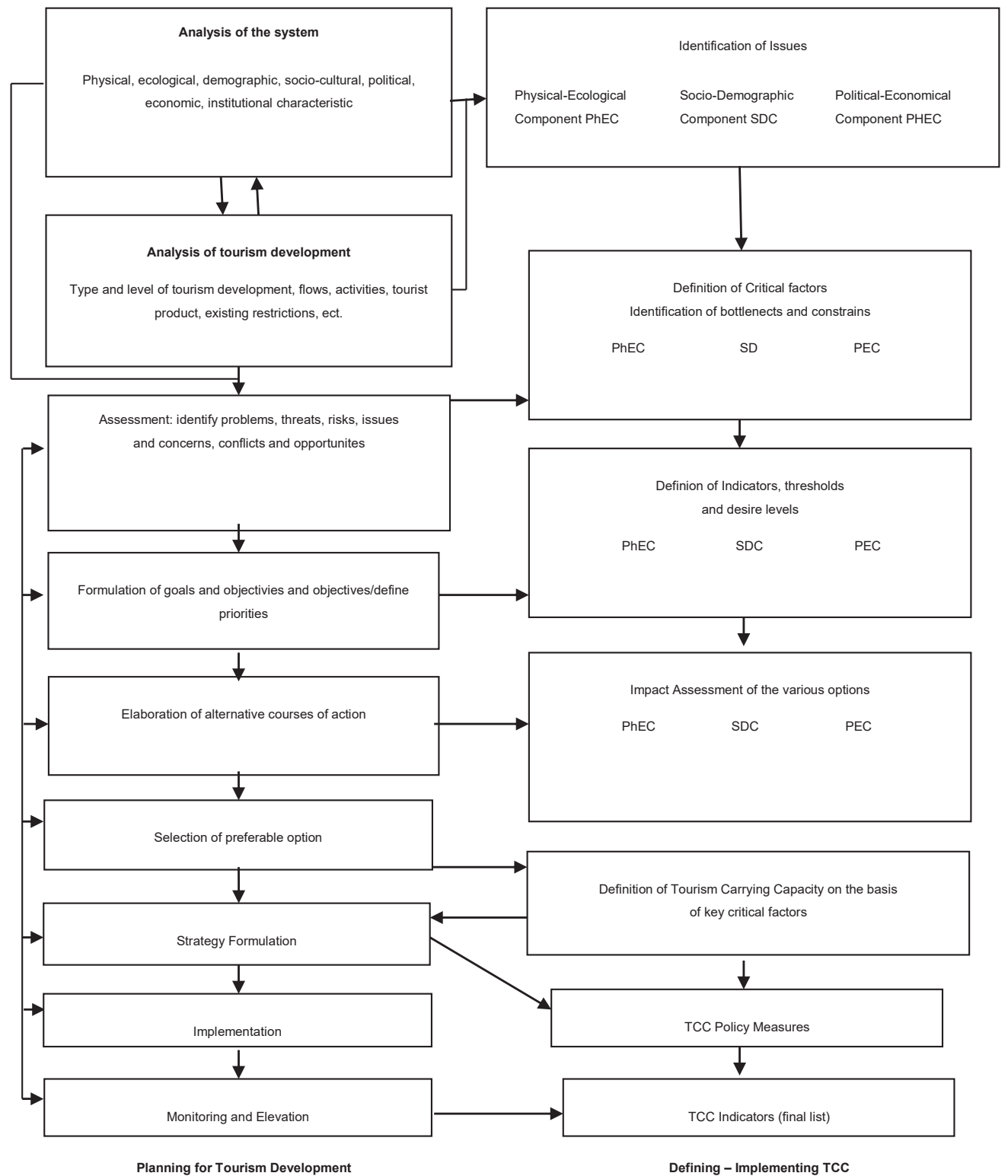

Figure 4. The main steps of a process which could be used to define (and implement) TCC

Source: Coccossis, Mexa (2002). 


\section{Results - The comparison of the motivation to visit other part of the region focusing on the creative industry aspects}

The number of respondents defining the following aspects as strongly influencing their decision to visit the other part region (other country) as a tourism destination

As we can see at Figure 5 the strong and rather strong motivation among German tourists is higher in 5 out of 6 aspects. Tourists at the German side are motivated by both market differences like prices and different products, but also by curiosity about landscape and cultural attractions. The highest mentioned motivator by German tourists is the curiosity of the landscape and natural heritage $24 \%$, among Poles it is one of the lowest, because $5 \%$ of Poles chose this aspect as a motivating one. Adding to this the interest of the German tourist in cultural offer and history ( $13 \%$ of German tourist pointed that), it gives us a picture of a very conscious tourist. The German tourist is also motivated by the purchase offer $-22 \%$ of the respondents chose this answer as a motivating one, and it was also the most frequently chosen indicator by Polish tourists $-13 \%$. In general German tourists are much more motivated to visit polish side of the coast then Polish tourists the German side.

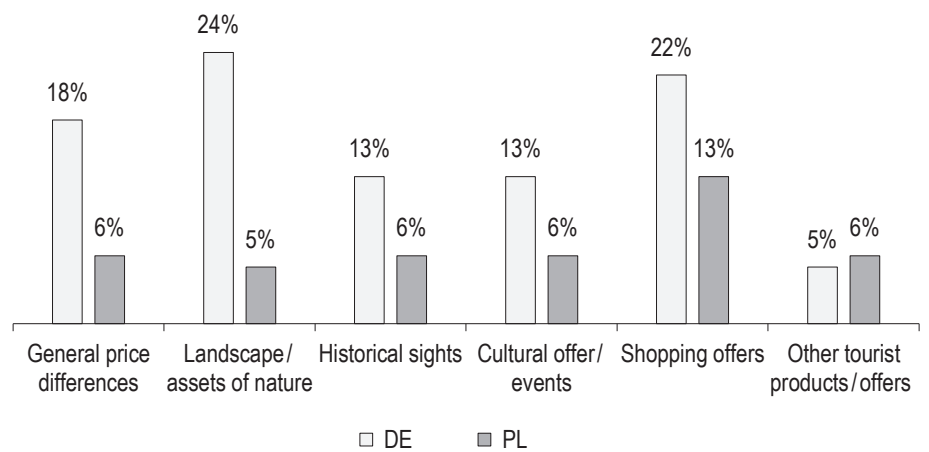

Figure 5. Motivation to go travel to neighbouring country

Source: own resources.

When tourist was asked about obstacles and barriers in travelling to other country the biggest difference between Poles and German was the price of the services offered (Figure 6) 40\% of Polish respondents indicated this reason as the most serious in their decision to spend their holidays in a neighbouring country, with only $14 \%$ of respondents in Germany. It is worth noting that German tourists still perceive our country as attractive in terms of prices. The highest rate of $22 \%$ among German tourists is the lack of interest. German tourists do not have adequate knowledge and information about what to expect from the Polish side, so they do not even think about making travel decisions. Among Poles, this rate is also high, i.e. as much as $40 \%$. It may be concluded that in order to deepen the knowledge and desire to visit the country of the neighbour, it is necessary to carry out information and promotion campaigns showing tourist and cultural attractions. 
Among the Polish respondents, the indicator concerning the level of crime was the least frequently chosen. Polish tourists perceive the German coast as a peaceful and safe place to relax. Germany cited this factor as $16 \%$ and was the third highest after a lack of interest and language difficulties.

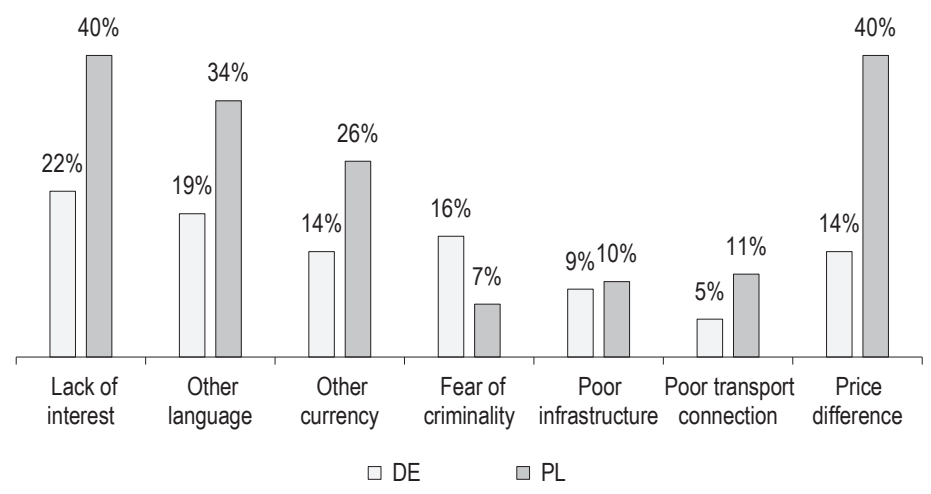

Figure 6 . Obstacles in going to neighbouring country

Source: own recourse.

\section{Conclusions}

As the society has developed and was able to fulfill the basic needs for food and shelter they turned their attention to satisfaction of "higher order" needs, such as satisfaction and self-fulfillment. Scitovsky (1976) has described this development in terms of the shift from unskilled to skilled consumption, or from outer directed to inter directed consumption. Culture and tourism were two of the main growth industries in the $20^{\text {th }}$ century, and the combination of both "cultural tourism" had become popular and profitable development option for regions and countries around the world. In 2007 cultural tourism accounted almost $360 \mathrm{mln}$ international tourist, or $40 \%$ global tourism. In value terms the condition of cultural tourism is even greater, because cultural tourist is estimated to spend as much as one third more on average than another tourist. Nevertheless, the rapid growth of tourist has raised the questions about sustainability of this new form of mass tourism, because cultural mass tourism brought several negative impacts as overcrowding, environmental problems, degradation of local culture. It made regions start searching for new forms of articulation between culture and tourism, which can strengthen rather than water down regional culture. As trend appear that people don't want longer to concentrate on accumulating of goods, but rather there are keen to develop themselves doing creative things as drawing, painting, singing and doing yoga etc. - all these activities which build their own skills and develop their potential.

Ironically, skilled consumers know more about the experiences they are consuming then the people who supposed to supply them. $21^{\text {st }}$ century is the time when travelers construct their own itineraries on the Internet; they no longer buy the packaged excursion, but creatively shape their own experiences, based on what, when and where they want to see. These experiences emphasize active involvement in local culture and creativity rather than the top lists of global culture. Creative tourism - the new forms of tourism are difficult for the traditional tourism sector to 
deal with, but in case of not risking losing the clients; there are more opportunities in dealing with them than ignoring creative tourism.

According to Richard and Raymond: creative tourism is the one which offers visitors the opportunity to develop their creative potential through active participation in courses and learning experiences which are characteristic of the holiday destination where they are undertaken. Important implications:

Creative potential - the tourist is provided with tools to develop their own creative potential, and to take something more than souvenirs home with them.

Active involvement - tourists are actively involved in the creative process, and this involvement creates the potential for genuine exchange and engagement with local people and culture.

Characteristic experience - creativity can happen everywhere, but good thing is to link the creative process to destination, local culture and identity.

Co-creation - the concept of creative tourism implies a level of co-creation, co-makership between tourists and locals.

\section{Referencees}

Bimonte, S., Punzo, L.F. (2007). The evolutionary game between tourist and resident populations and Tourist Carrying Capacity. International Journal of Technology and Globalisation, 3 (1), 73-87.

Briassoulis, H. (2002). Sustainable tourism and the question of the commons. Annals of Tourism Research, 29 (4), $1065-1085$.

Coccossis, H., Mexa, A. (2002). Defining, measuring and evaluating carrying capacity in European tourism destinations. B4-3040/2000/294577/MAR/D2. Athens. Retrieved from: http://ec.europa.eu/environment/iczm/pdf/tcca_material.pdf.

Kubicki, P. (2010). Nowi mieszczanie w nowej Polsce. Raport. Retrieved from: www.instytutobywatelski.pl/files/attachment/ksiega_ mieszcz_1.pdf.

PAP/RAC (1997). Guidelines for carrying capacity assessment for tourism in Mediterranean coastal areas. PAP/1997/G.1. Spilt: Priority Actions Programme Regional Activity Centre. Retrieved from: https://www.pap-thecoastcentre.org/pdfs/Guidelines $\% 20$ CCA $\% 20$ Tourism.pdf.

Robinson, M. (2000). Collaboration and Cultural Consent: Refocusing Sustainable Tourism. In: B. Bramwell, B. Lane (eds), Tourism Collaboration and Partnerships: Politics, Practice and Sustainability. Clevedon: Channel View Publications.

Shelby, B., Heberlein, T.A. (1986). Carrying Capacity in RecreationSettings. Oregon State University Press.

Cite this article aS: Tomczyk, M. (2018). Capacity of the tourism and the role of creative industries - perception of visitors, barriers and motivation. European Journal of Service Management, 3 (27/2), 489-498. DOI: 10.18276/ejsm.2018.27/2-60. 